\title{
YIELD LOCI OF ANISOTROPIC SHEET METALS
}

\author{
Christian Vial ${ }^{\dagger}$ and William F. Hosford \\ Department of Materials and Metallurgical Engineering. The University of Michigan, \\ Ann Arbor, MI 48109, U.S.A.
}

and

Robert M. CADDELL

Department of Mechanical Engineering and Applied Mechanics, The University of Michigan, Ann Arbor, MI 48109, U.S.A.

(Received 20 August 1982; in revised form 20 January 1983)

\begin{abstract}
Summary-Four sheet metals, having quite different combinations of $\boldsymbol{R}$-values and strainhardening behavior were tested in uniaxial tension, uniaxial (through thickness) compression, balanced biaxial tension (bulge test), and plane-strain compression. The results were compared with predictions based upon three different anisotropic yield criteria. Although no single yield criterion proved to describe adequately all of the test results, different criteria provided the best agreement with particular metals. Results from through-thickness compression and bulge tests were nearly identical.

In bulge testing, strains were determined from photographs of printed grids while the radius of curvature at the top of the dome was obtained using a projected fringe technique that involved a holographic grating. Radii measured by this technique were smaller for all materials than those measured by the conventional spherometer.
\end{abstract}

\section{NOTATION}

a exponent in Hosford's yield criterion, equation (5)

$B$ flow stress in biaxial tension

$d$ distance between fringes

$D, E, F$ coefficients of equation that fits curvature of bulged sheet

$h_{i}$ vertical coordinate of bulged surface at fringe $i$

$i$ fringe order

$k$ parameter in equation (14)

$K$ strength coefficient in power-law hardening expression

$m$ exponent in Hill's "new" yield criterion, equation (4)

$n$ strain hardening exponent

$p$ pressure

$P$ strain ratio in transverse direction tension test

$P S_{x}, P S_{y}$ flow stress in plane strain with $\epsilon_{x}=0$ and $\epsilon_{y}=0$ respectively

$r_{t}, r_{i}$ radii of curvature of the external and internal surfaces of the bulged sheet

$r_{x}, r_{y}$ two orthogonal radii of curvature through the dome of the bulge

$R$ strain ratio in rolling direction tension test

$\bar{R}$ average strain ratio

$R_{\theta}$ strain ratio in tension test at angle $\theta$ to rolling direction

$t, t_{0}$ instantaneous and initial sheet thickness respectively

$x_{i}$ horizontal coordinate of bulged surface at fringe $i$

$X$ flow stress in rolling direction tension test

$w$ plastic work per unit volume

$Y$ flow stress in transverse direction tension test

$\bar{Y}$ average flow stress in tension

$\alpha$ angle of incidence between laser beam and horizontal

$\alpha_{x}, \alpha_{y}$ parameters in equation (13b) and (13c)

$\epsilon$ true strain

$\sigma$ true stress

Subscripts

$x, y, z$ rolling, transverse and thickness directions

$l, w, t$ length, width and thickness direction of a tensile specimen

1.2 generalized loading paths

$\div$ Present address: Department of Mechanical and Metallurgical Engineering Pontificia Universidad Católica de Chile. Santiago. Chile. 


\section{INTRODUCTION}

To test the validity of an anisotropic yield criterion, two approaches are widely used. In one, balanced biaxial tensile behavior is predicted from uniaxial tensile test results and compared with experimental findings obtained from a bulge test. Since the findings from such a uniaxial test are obtained using an accurate extensometer and load cell and would seem subject to little error, any differences between predicted and measured behavior in bulge testing must be due to one of two sources. Either the accuracy of measurements is open to question or the yield criterion used for predictive purposes does not adequately describe the material's behavior. The second approach compares predicted yield loci with experimental points measured from different loading paths. Both approaches are addressed in this paper.

In the majority of studies to date, what we call Hill's "old" criterion [1, 2] has been used to compare prediction and experiment. For plane-stress conditions this criterion can be expressed as,

$$
R \sigma_{y}^{2}+P \sigma_{x}^{2}+R P\left(\sigma_{x}-\sigma_{y}\right)^{2}=P(R+1) X^{2}
$$

where $x, y$, and $z$ denote the rolling, transverse, and through-thickness directions respectively, $R$ and $P$ represent the strain ratios in the rolling and transverse directions, and $X$ is the tensile yield stress in the $x$ direction.

Based upon reported findings, (e.g. [3-8]), Hill's old criterion gives a better correlation with metals having an average strain ratio, $\bar{R}$, greater than one but is less acceptable where $\bar{R}$ is less than one. Here,

$$
\bar{R}=1 / 4\left(R+2 R_{45}+P\right)
$$

where the $R_{45}$ value is determined using a specimen cut at $45^{\circ}$ from the rolling direction.

For planar isotropy (i.e. $R=P=R_{45}$ ), equation (1) reduces to,

$$
\sigma_{x}^{2}+\sigma_{y}^{2}+R\left(\sigma_{x}-\sigma_{y}\right)^{2}=(R+1) X^{2} .
$$

In many cases, equation (3) has been used with $\bar{R}$ instead of $R$ even though planar isotropy did not exist. Though reasonable correlations have been found, such practice is not theoretically justified.

Recently, Hill[9] has proposed a very general anisotropic yield criterion and suggested four abbreviated forms for in-plane isotropy and plane-stress loading. The only form which appears to have been compared with experiment (e.g. $[10,11])$ is:

$$
\left|\sigma_{x}+\sigma_{y}\right|^{m}+(1+2 R)\left|\sigma_{x}-\sigma_{y}\right|^{m}=2(1+R) X^{m} .
$$

(Note that if $m=2$, equation (4) reduces to equation (3).) One example of its use has been to explain the finding by Woodthorpe and Pearce [12] that aluminum sheets with $\bar{R}=0.5$ and 0.6 had yield strengths in biaxial tension 1.1 times those in uniaxial tension. According to equation (3), if $\bar{R}<1$, the biaxial strength must be less than the uniaxial stress, but Parmar and Mellor[10] showed that these "anomalous" results are consistent with equation 4 with $m$-values of 1.47 and 1.38 .

Hosford $[13,14]$ independently proposed a somewhat less general modification of Hill's "old" criterion:

$$
R \sigma_{y}{ }^{a}+P \sigma_{x}^{a}+R P\left|\sigma_{x}-\sigma_{y}\right|^{a}=P(1+R) X^{a} .
$$

This also is a special form of Hill's new general criterion, but one which can not be adapted to explain the Woodthorpe-Pearce "anomaly." In contrast to equations (3) and (4), equation (5) does not assume planar isotropy. Yield loci calculations based on crystallographic models suggested that the value of the exponent $a$ is 8 for FCC 
metals and 6 for BCC metals, so the $a$-value is not taken as an adjustable parameter in this paper.

The experimental results in this paper are analyzed in terms of equation (1), (3)-(5).

\section{EXPERIMENTAL STUDIES}

(a) Materials

Sheets of four materials were received in an annealed condition and received no subsequent heat treatment. They were,

(1) Aluminum-killed (AK) steel, $0.89 \mathrm{~mm}(0.035 \mathrm{in}$.) thick.

(2) Aluminum alloy $3003-0,1 \mathrm{~mm}(0.040 \mathrm{in}$.) thick.

(3) Copper-110, $0.75 \mathrm{~mm}(0.030 \mathrm{in}$.) thick. According to the manufacturer, 30 to $35 \%$ of the grains were in a cube orientation.

(4) Brass 260 (70\% copper. $30 \%$ zinc), $0.75 \mathrm{~mm}$ ( 0.030 in.) thick.

\section{(b) Uniaxial tension tests}

Specimens produced from material oriented at 0,45 and $90^{\circ}$ to the rolling direction were subjected to standard tensile tests, strains being determined with the aid of a $50 \mathrm{~mm}$ extensometer. The curves and property values discussed later are based upon average values of two to four individual tests. Although the initial strain rate varied, the extremes were from $2.5 \times 10^{-4} \mathrm{sec}^{-1}$ to $1.5 \times 10^{-3} \mathrm{sec}^{-1}$. Separate specimens. produced at 0,45 and $90^{\circ}$, were used to determine the plastic strain ratios with the aid of photographic grids printed on the gage sections. These specimens were stretched to 4 or 5 levels of longitudinal strain in the range of 2-25\%. Strains were computed from dimensional changes measured with a traveling microscope calibrated to $0.025 \mathrm{~mm}\left(0.001 \mathrm{in}\right.$.). The strain ratios, whether $R, P$ or $R_{45}$ were determined from,

$$
R_{\theta}=d \epsilon_{w} / d \epsilon_{t}=-d \epsilon_{w} /\left(d \epsilon_{t}+d \epsilon_{w}\right)
$$

where $\theta$ refers to the specimen orientation and $d \epsilon_{l}$ and $d \epsilon_{w}$ refer to the longitudinal and width strains of the gage section. No significant variation was found as a function of strain level.

(c) Bulge tests (balanced biaxial tension)

Even though much information on bulge testing has been published, one equation has remained when anisotropic metals are used. That is, does the radius of curvature depend upon the orientation along which such measurements are made? The most widely used device for determining strains and the radius of curvature is the spherometer-extensometer developed by Duncan and Johnson[15]. With such a unit, the radius of one great circle passing through the top of the bulged dome is determined. Published work by Dudderar et al.[16], wherein copper foils were bulged, indicated that the radius of curvature varied with orientation through the dome top. Whether such a finding would result with sheet metal was not known so an investigation was pursued. A projected fringe technique similar to that used with foil[16] was modified by recommendations of Vest [17]. A $5 \mathrm{~mW} \mathrm{He}-\mathrm{Ne}$ laser generated a beam of polarized coherent light; this was expanded ten times by a collimator to a diameter of $15 \mathrm{~mm}$. This beam was passed through a holographic grating previously produced by a double exposure of two nearly parallel laser beams as described elsewhere [18]. In effect, the holographic grating reconstructed original beams, and interference of the reconstructed beams produced a set of parallel planes of light separated by equidistant dark fringes directed at the bulged surface.

The laser and grating were so positioned that the reconstructed beam made an angle of $27.5^{\circ}$ with the horizontal; this angle was a compromise between an increased area of illumination and inçreased sensitivity of the distance measured between fringes to the curvature of the bulged surface. Fig. 1 is a typical photograph of fringes during bulging. In Fig. 2(a), the geometry of a bulged surface is sketched, while Fig. 2(b) shows an enlarged view of a portion of the surface which assists in explaining how the radius of curvature was computed.

Nine coordinate points on an arc about $20 \mathrm{~mm}$ long were found by measuring the horizontal distance $x_{\mathrm{i}}$ of each fringe from a reference fringe, $x_{0}$; the corresponding vertical component, $h_{i}$, was computed from,

$$
h_{i}=i d l \cos \alpha-x_{i} \tan \alpha
$$

where: $I=$ order of fringe with respect to fringe zero; $d=$ perpendicular distance between dark fringes $(0.226 \mathrm{~mm})$; and $\alpha=$ angle of incidence between laser beam and the horizontal $\left(27.5^{\circ}\right)$

Coordinates of the nine points were used to find the least squares fit to a parabola of the form,

$$
h=D+E x+F x^{2} .
$$

The external radius of curvature, $r_{e}$ at any distance $x$ is given by,

$$
r_{e}=\left[1+(E+2 F x)^{2}\right]^{1.5} /(2 F) \text {. }
$$

Although the value of $r_{e}$ at the center of the dome was of prime concern, it is interesting to note that over the range of $x$ values considered, the term $(E+2 F x)$ was much less than unity so $r_{c}$ was nearly constant and the shape of the specimen was very close to the arc of a circle.

A second degree polynomial, i.e. equation (8), was chosen instead of one of higher degree because the latter tends to follow the irregularities of experimental points thereby leading to excessive variations in the radius of curvature. It is possible in the foil study mentioned earlier[16], the method used to calculate the radius was subject to such an effect. 
๑.
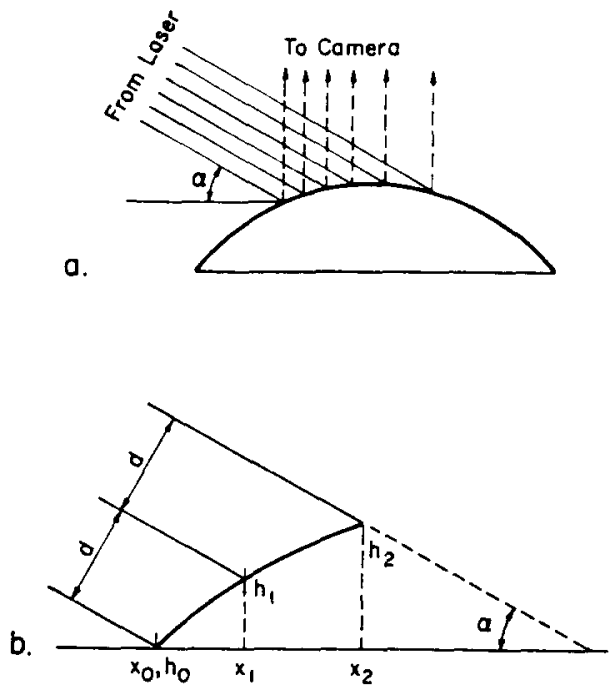

FiG. 2. (a) Geometry of bulge profile with impinging laser beam. (b) Enlarged sketch of (a) illustrating how coordinate points on bulged surface were computed.

Because the laser could not be rotated, two tests were needed to determine the radius of curvature in both the rolling and transverse directions; in essence, the two specimens were oriented $90^{\circ}$ from each other when they were clamped individually in the bulge fixture. No significant difference was found in plots of $r_{e}$ versus pressure from these tests so if was felt that a third test (specimen oriented $45^{\circ}$ from the other two) was unnecessary. Data from both tests were plotted together, fitted with a single, best-fit equation as in equation (9), and a single value of $r_{e}$ was assumed for all directions. Therefore, the biaxial flow stress. $B$, was calculated from,

$$
B=p r_{i}^{2} /\left(r_{e}^{2}-r_{i}^{2}\right)+p / 2
$$

where $p$ is the pressure and $r_{i}$ and $r_{e}$ are the radii of the internal and external surfaces of the bulge. Equation (10) results from integrating the biaxial stresses across the thickness and considering the effect of the average through-thickness stress which varies from- $p$ on the inside to zero at the outside. Expressions giving results similar to equation (10) can be found in the literature [19].

Strains were determined from a photographically printed grid of squares, $6.4 \mathrm{~mm}$ by $6.4 \mathrm{~mm}$, produced on the specimen prior to bulging. The sides of the squares corresponded to the rolling and transverse directions of the sheet. At a given pressure, when photographs of the fringes were made to assess the radius of curvature, a separate photograph, using normal illumination, was made of the distorted grid. Fig. 3 shows a typical photograph. During bulging, the external surface elongates more than the internal surface so the measured external strains were corrected using a mid-surface radius defined as,

$$
r=\left[\left(r_{e}^{2}+r_{i}^{2}\right) / 2\right]^{1 / 2}
$$

where $r_{i}=r_{e}-t$.

Each bulge test was conducted with a specimen adapted to a $101.6 \mathrm{~mm}(4 \mathrm{in}$.) bulge tester. A special hydraulic system controlled the flow rate of oil which allowed careful control of the rate of bulging. After increasing the pressure to a preselected level, it was lowered about 40 psi to avoid creep while the photographs were taken. This procedure was continued to ever increasing levels of pressure to provide an adequate amount of data; no tests were carried to fracture. Strain rates were estimated by measuring the time spent in increasing the pressure to its next level and determining the corresponding strain increment during that interval. By this method, the range of strain rates for all tests was from $20 \times 10^{-3} \mathrm{sec}^{-1}$ to $2.5 \times 10^{-3} \mathrm{sec}^{-1}$. Pressure was measured with a calibrated digital pressure gage having a range from 0 to 1500 psi. In a few cases, photographs of fringes were taken with the pressure completely removed to determine if elastic springback caused any noticeable change in the radius or curvature; no meaningful change was observed.

\section{(d) Plane-strain compression tests}

These tests were run using a typical Ford-type apparatus [20] where the indenters had a breadth (b) of $4.1 \mathrm{~mm}$. The contact length (w) varied between 64 and $66 \mathrm{~mm}$ while the initial thickness, $t_{0}$, was given for each material earlier. These dimensions are in close correspondence for the $(b / t)$ and $(w / b)$ ratios recommended by Johnson and Mellor [19].

One series of tests was done with a mixture of molybdenum disulfide and Vaseline as a lubricant, whereas a duplicate series employed Tefion tape $0.076 \mathrm{~mm}(0.003$ in.) thick. We note here that a smoother surface resulted when the mixture of moly-disulfide and Vaseline was used. An attempt was made to use the suggestion by Alexander[21] for determining the frictionless yield stress in plane-strain compression. This proved unsuccessful and is not discussed further.

Each specimen was indented at successively increasing loads but in different locations along the 


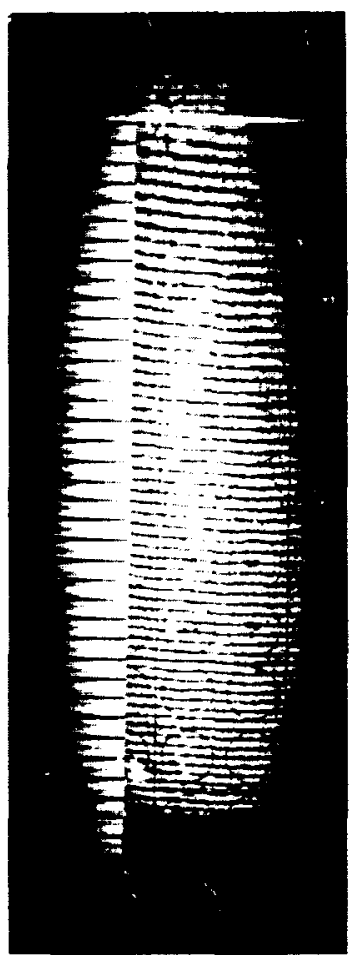

FIG. 1. Typical photograph of projected fringes with a millimeter scale above.

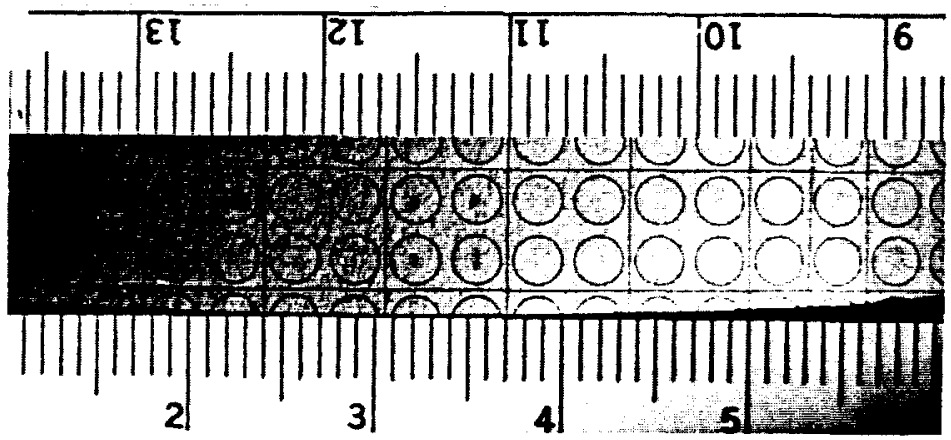

FIG. 3. Typical photograph of printed grid at top of bulge with reference scales. 

specimen. After applying and then removing each load, the indented thickness was measured at five locations and then averaged.

For these tests, constant crosshead speeds of 0.02 and $0.008 \mathrm{~mm} / \mathrm{sec}$ were used. By timing the interval per indentation and then computing the strain induced, estimates of strain rate were made. The range of initial strain rates for all materials varied from $1.5 \times 10^{-3} \mathrm{sec}^{-1}$ to $6 \times 10^{-3} \mathrm{sec}^{-1}$.

(e) Uniaxial compression tests

Because a balanced biaxial state of tension plus a proper hydrostatic pressure produces a stress state that is equivalent to uniaxial compression in the through-thickness direction, bulge test results and those from direct uniaxial compression should, theoretically, give the same stress-strain curves. Of course with thin sheet metal, conducting an acceptable compression test is questionable because of frictional effects at the loading surfaces. Instead, a technique was used to prepare "compression" specimens that would minimize that problem. A series of twenty discs was blanked from each sheet material using a punch and die. These were stacked together (no glue or bonding agent was used) and machined in a lathe to produce a "cylindrical" specimen that represented a right circular cylinder. Tape was then applied to the periphery to maintain alignment of the stack during handling. A few of the end discs, damaged during machining, were discarded so that the final specimens had height to diameter ratios from 0.8 to 1.2 . Tefion tape of $0.075 \mathrm{~mm}$ ( 0.003 in.) thickness was placed between the specimen ends and the platens for lubrication. Crosshead speeds of 0.01 and $0.02 \mathrm{~mm} / \mathrm{sec}$ were used and two tests were completed for each material. Estimated strain rates, using the procedure discussed earlier. ranged from $0.6 \times 10^{-3} \mathrm{sec}^{-1}$ to $1.3 \times 10^{-3} \mathrm{sec}^{-1}$

Loads were applied in increasing increments. After reaching a particular load, it was then fully removed and the length and diameter measured. During initial loading, the discs were merely flattened (naturally. all mating disc surfaces were not truly flat at the outset) and no appreciable change in diameter was noted. For strain calculations, the "starting" height was taken as the height after the load increment just priof to the first observed increase in diameter. Up to reasonably high strains, no barrelling was observed but, eventually, the diameters began to vary with location. When this occurred, the specimen was removed and remachined to a uniform diameter; the test was then continued using this new diameter for further computations of stress and strain.

\section{RESULTS}

The experimental data for each test were fitted to a power law expression, $\sigma=K \epsilon^{n}$, using the method of least squares. For all .cases, the square of the correlation coefficient was at least 0.99 . All results are tabulated in Tables 1-3 noting that the strain ratios are also listed in Table 1.

\section{ANALYSIS OF RESULTS}

The yield criteria, equations (1), (4) and (5) can be used to predict the ratio of stresses along different loading paths but at the same level of plastic work per volume. Expressions of such ratios for the loading paths of interest are given below using equations (1), (4) and (5).

From equation (1),

$$
\frac{B}{X}=\left[\frac{P(R+1)}{(R+P)}\right]^{1 / 2}, \text { and } \frac{P S_{y}}{X}=\frac{P S_{x}}{Y}=\left[\frac{(R+1)(P+1)}{(R+P+1)}\right]^{1 / 2}
$$

where $X$ and $Y$ are the uniaxial tensile flow stresses in the $x\left(0^{\circ}\right)$ and $y\left(90^{\circ}\right)$ directions, $B$ is the flow stress in biaxial tension, $P S_{y}$ is the flow stress under plane strain where $\epsilon_{y}=0, P S_{x}$ is the flow stress under plane strain where $\epsilon_{\mathrm{x}}=0$, and $R$ and $P$ are the strain ratios in the 0 and $90^{\circ}$ tension tests.

Table 1. Uniaxial tension tests

\begin{tabular}{|c|c|c|c|c|c|}
\hline & & & & & \\
\hline MATER IAL & $\begin{array}{c}\text { ANGLE } \\
\left({ }^{\circ}\right)\end{array}$ & $\begin{array}{c}K \\
(\mathrm{MPa})\end{array}$ & $\mathbf{n}$ & $\begin{array}{l}\text { RANGE OF } \\
\text { STRAIN }\end{array}$ & $\begin{array}{l}\text { STRAIN RATIO } \\
\text { (R) }\end{array}$ \\
\hline $\begin{array}{c}\text { Al-killed } \\
\text { Steel }\end{array}$ & $\begin{array}{l}0 \\
90 \\
45 \\
\text { av }\end{array}$ & $\begin{array}{l}520.2 \\
511.8 \\
533.0 \\
524.9\end{array}$ & $\begin{array}{l}0.237 \\
0.235 \\
0.233 \\
0.234\end{array}$ & $\begin{array}{l}0.02-0.24 \\
0.02-0.24 \\
0.02-0.24 \\
0.02-0.24\end{array}$ & $\begin{array}{l}1.950 \\
2.318 \\
1.470 \\
1.802\end{array}$ \\
\hline Aluminum & $\begin{array}{r}0 \\
90 \\
45 \\
\text { av }\end{array}$ & $\begin{array}{l}195.5 \\
183.2 \\
187.1 \\
183.1\end{array}$ & $\begin{array}{l}0.214 \\
0.215 \\
0.222 \\
0.218\end{array}$ & $\begin{array}{l}0.02-0.24 \\
0.02-0.24 \\
0.02-0.24 \\
0.02-0.24\end{array}$ & $\begin{array}{l}0.655 \\
0.510 \\
0.753 \\
0.668\end{array}$ \\
\hline Copper & $\begin{array}{r}0 \\
90 \\
45 \\
\text { av }\end{array}$ & $\begin{array}{l}465.7 \\
433.9 \\
436.8 \\
443.3\end{array}$ & $\begin{array}{l}0.362 \\
0.364 \\
0.361 \\
0.362\end{array}$ & $\begin{array}{l}0.02-0.28 \\
0.02-0.31 \\
0.02-0.36 \\
0.02-0.28\end{array}$ & $\begin{array}{l}0.870 \\
0.848 \\
0.449 \\
0.654\end{array}$ \\
\hline Brass 260 & $\begin{array}{r}0 \\
90 \\
45 \\
\text { av }\end{array}$ & $\begin{array}{l}828.8 \\
828.6 \\
809.7 \\
819.2\end{array}$ & $\begin{array}{l}0.493 \\
0.498 \\
0.495 \\
0.495\end{array}$ & $\begin{array}{l}0.03-0.39 \\
0.08-0.39 \\
0.08-0.39 \\
0.08-0.39\end{array}$ & $\begin{array}{l}0.944 \\
0.743 \\
0.841 \\
0.842\end{array}$ \\
\hline
\end{tabular}


Table 2. Biaxial tension and uniaxial compression tests

\begin{tabular}{|c|c|c|c|}
\hline Material & $\begin{array}{c}k \\
\left(M P^{2} a\right)\end{array}$ & $\pi$ & $\begin{array}{c}\text { Range of } \\
\text { Strain }\end{array}$ \\
\hline \multicolumn{4}{|c|}{ Biaxial Tension Stress vs. Thickness Strain Curves } \\
\hline Al-killed Steel & 12.6 & 0.278 & $0.06-0.25$ \\
\hline Aluminum 3003-0 & 171.3 & 0.170 & $0.055-0.33$ \\
\hline Copper 110 & 444.6 & 0.368 & $0.09-0.42$ \\
\hline Brass 260 & 548.0 & 0.465 & $0.10-0.25$ \\
\hline
\end{tabular}

Uniaxial Conpression Stress vs. Thickness Strain Curves

\begin{tabular}{l|c|c|c}
\hline Al-killed Steel & 661.2 & 0.248 & $0.013-0.27$ \\
Alurinum 3005-0 & 176.9 & 0.2054 & $0.027-0.35$ \\
Copper 110 & 418.3 & 0.354 & $0.025-0.32$ \\
Brass 260 & 787.8 & 0.442 & $0.065-0.24$ \\
\hline
\end{tabular}

Table 3. Plane-strain compression tests

\begin{tabular}{|c|c|c|c|c|}
\hline MATERIAL & $\begin{array}{c}K \\
(\mathrm{MPa})\end{array}$ & $\bar{n}$ & $\begin{array}{l}\text { RANGE OF } \\
\text { STRAIN }\end{array}$ & LUBRICANT \\
\hline & a) & ne Strain & Compression & \multirow{2}{*}{ 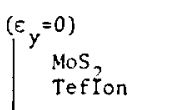 } \\
\hline Al-killed Steel & $\begin{array}{l}805.0 \\
812.0\end{array}$ & $\begin{array}{l}0.256 \\
0.268\end{array}$ & $\begin{array}{l}0.055-0.36 \\
0.055-0.35\end{array}$ & \\
\hline *Aluminum 3003-0 & 212.7 & 0.204 & $0.03-0.35$ & $\mathrm{MoS}_{2}$ \\
\hline Copper 110 & $\begin{array}{l}505.9 \\
448.9\end{array}$ & $\begin{array}{l}0.369 \\
0.304\end{array}$ & $\begin{array}{l}0.04-0.36 \\
0.10-0.37\end{array}$ & $\begin{array}{l}\text { Mos, } \\
\text { TefIon }\end{array}$ \\
\hline Brass 260 & $\begin{array}{r}1012.9 \\
950.5\end{array}$ & $\begin{array}{l}0.469 \\
0.457\end{array}$ & $\begin{array}{l}0.07-0.29 \\
0.06-0.31\end{array}$ & $\begin{array}{l}\text { Mos, } \\
\text { Tefion }\end{array}$ \\
\hline
\end{tabular}

b) Plane Strain Compression $\left(\varepsilon_{X}=0\right)$

\begin{tabular}{|c|c|c|c|c|}
\hline Al-killed Steel & $\begin{array}{l}826.9 \\
836.1\end{array}$ & $\begin{array}{l}0.259 \\
0.266\end{array}$ & $\begin{array}{l}0.05-0.31 \\
0.05-0.27\end{array}$ & $\begin{array}{l}\text { MoS, } \\
\text { TefIon }\end{array}$ \\
\hline *Aluminum 3003-0 & 197.4 & 0.214 & $0.02-0.5$ & $\mathrm{MoS}_{2}$ \\
\hline Copper & $\begin{array}{l}483.8 \\
497.2\end{array}$ & $\begin{array}{l}0.362 \\
0.356\end{array}$ & $\begin{array}{r}0.075-0.41 \\
0.08-0.33\end{array}$ & $\begin{array}{l}\text { Mos, } \\
\text { Tefion }\end{array}$ \\
\hline Brass 260 & $\begin{array}{l}927.4 \\
951.7\end{array}$ & $\begin{array}{l}0.453 \\
0.471\end{array}$ & $\begin{array}{l}0.07-0.34 \\
0.09-0.34\end{array}$ & $\begin{array}{l}\mathrm{MoS}_{2} \\
\text { Tefton }\end{array}$ \\
\hline
\end{tabular}

* When teflon was used with aluminum, results were questionable

Similar expressions using equation (5) are,

$$
\begin{gathered}
\frac{B}{X}=\left[\frac{P(R+1)}{(R+P)}\right]^{1 / a} \\
\frac{P S_{y}}{X}=\left[\frac{P(R+1)}{R \alpha_{y}{ }^{a}+P+R P\left(1-\alpha_{y}\right)^{a}}\right]^{1 / a}
\end{gathered}
$$

where $\alpha_{y}=P^{1 /(a-1)} /\left[1+P^{1 /(a-1)}\right]$ and

$$
\frac{P S_{x}}{Y}=\left[\frac{R(P+1)}{P \alpha_{x}{ }^{a}+R+R P\left(1-\alpha_{x}\right)^{a}}\right]^{1 / a}
$$

where $\alpha_{x}=R^{1 /(a-1)} /\left[1+R^{1 /(a-1)}\right]$. 
Using equation (4),

$$
\frac{P S}{\bar{Y}}=\left[(1+k)(1+\bar{R})^{1 /(m-1)} /(2 k)\right]^{(m-11 / m}
$$

where $k=(1+2 \bar{R})^{1 /(m-1)}, \bar{R}$ is the average strain ratio, $\bar{Y}$ is the average tensile flow stress, and $P S$ is the flow stress in plane strain based upon planar isotropy.

The exponent, $m$. can be evaluated from the biaxial and uniaxial tests using the expression,

$$
m=\ln [2(1+\bar{R})] / \ln (2 B / \bar{Y}) .
$$

In each of the tests considered, the plastic work per volume is given by one term of the general expression

$$
w^{\prime}=\int \sigma_{x} d \epsilon_{x}+\int \sigma_{y} d \epsilon_{y}+\int \sigma_{z} d \epsilon_{z}
$$

In uniaxial tension, only one $\sigma$ term is finite, in plane strain one $\sigma$ term (e.g. $\left.\sigma_{y}\right)$ and one $\epsilon$ term (e.g. $\epsilon_{x}$ ) are zero, while balanced biaxial tension, $\sigma_{x}=\sigma_{y}$, is equivalent to uniaxial compression in the $z$ direction.

Assuming isotropic hardening, equations $(12)-(14)$ should hold at finite strains, so the ratio of flow stresses along two different loading paths, $\sigma_{2} / \sigma_{1}$, should be constant as long as $\sigma_{1}$ and $\sigma_{2}$ are evaluated at the same level of plastic work. Since $d w=\sigma_{1} d \epsilon_{1}=\sigma_{2} d \epsilon_{2}, d \epsilon_{1}=\left(\sigma_{2} / \sigma_{1}\right) d \epsilon_{2}$ and with $\sigma_{2} / \sigma_{1}$ being constant, integration gives.

$$
\epsilon_{1}=\left(\sigma_{2} / \sigma_{1}\right) \epsilon_{2}
$$

With power-law hardening, $\sigma_{l}=K_{1} \epsilon_{1}{ }^{n}$ along path one, then the stress-strain curve along path two should be,

$$
\sigma_{2}=K_{1}\left(\sigma_{2} / \sigma_{1}\right)^{n+1} \epsilon_{2}{ }^{n}
$$

Figs. 4-7 show the predictions of biaxial tension based upon uniaxial tension results using equations (12a) and (13a), which come from equations (1) and (5). In addition, equation (3) is also used with $\bar{R}$ and $\bar{Y}$ even though, as mentioned earlier, we feel this is incorrect. Note the excellent agreement between the biaxial tension and uniaxial compression experimental points. In these figures, no predictions are based upon Hill's "new" criterion since the experimental results themselves must be used to predict the exponent, $m$.

Figs. 8-11 show the experimental and predicted results for plane-strain compression.

Figs. 12-15 show yield loci predicted from equations (1), (4) and (5) where all stresses are normalized to the value of $X$. Note that with equations (1) and (5) the loci are forced to a value of one along the abscissa whereas equation (4) is forced to match the experimental value of biaxial tension results and does not match the value of one on the abscissa since it is based upon the average value of uniaxial tensile flow stresses.

Tables 4 and 5 contain the ratios of flow stresses calculated from equations (12)-(14), values of $\mathrm{m}$ calculated from equation (15) and the same ratios measured experimentally at strains of 0.1 in uniaxial tension and for other loading paths at strains producing the same amount of plastic work.

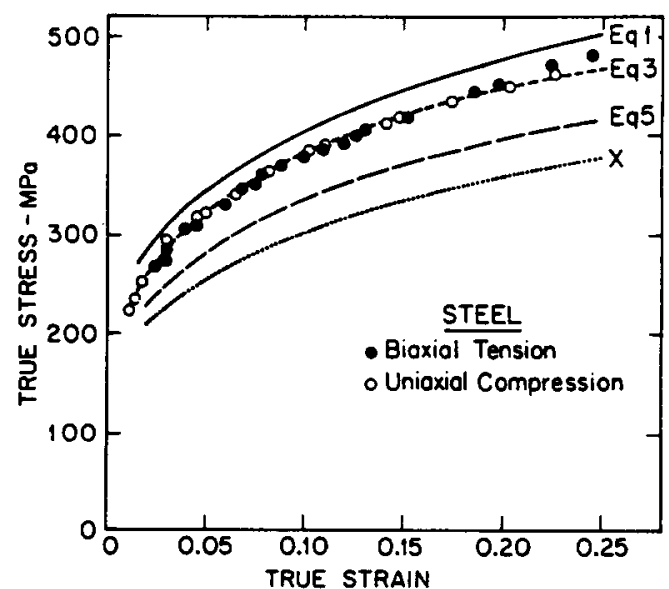

FIG. 4. Comparison of experimental biaxial tension and uniaxial compression points with predictions of various yield criteria from uniaxial tension test, $X$, in the rolling direction. Predictions from equation (3) are based upon average tension results. 


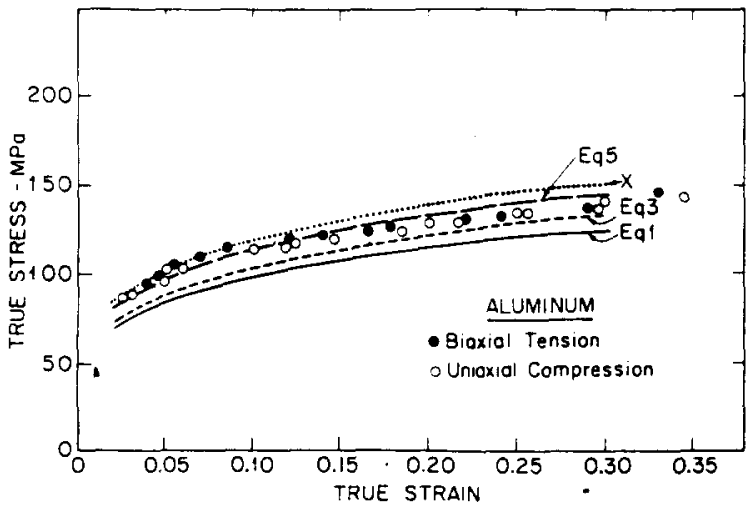

Fig. 5. Comparisons of experimental biaxial tension and uniaxial compression points with predictions of various yield criteria from uniaxial tension test, $X$, in the rolling direction. Predictions from equation (3) are based upon average tension results.

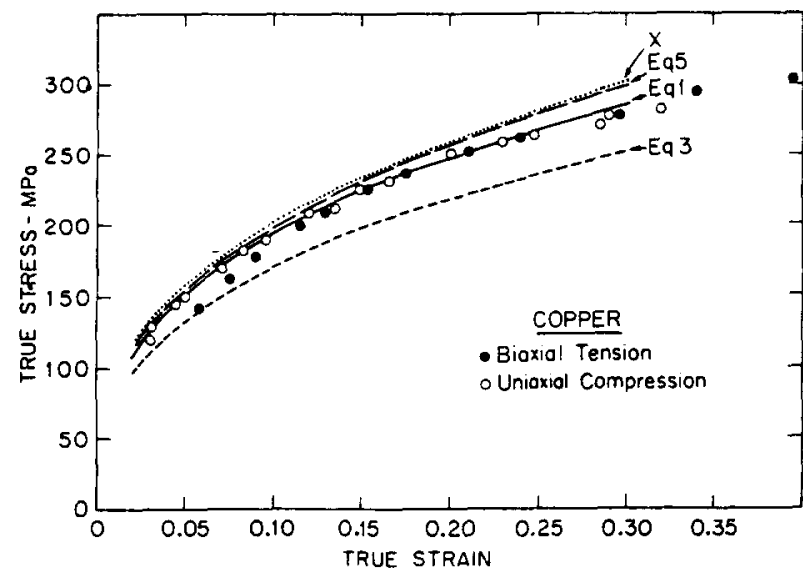

FIG. 6. Comparison of experimental biaxial tension and uniaxial compression points with predictions of various yield criteria from uniaxial tension, $X$, in the rolling direction. Predictions from equation (3) are based upon average tension results.

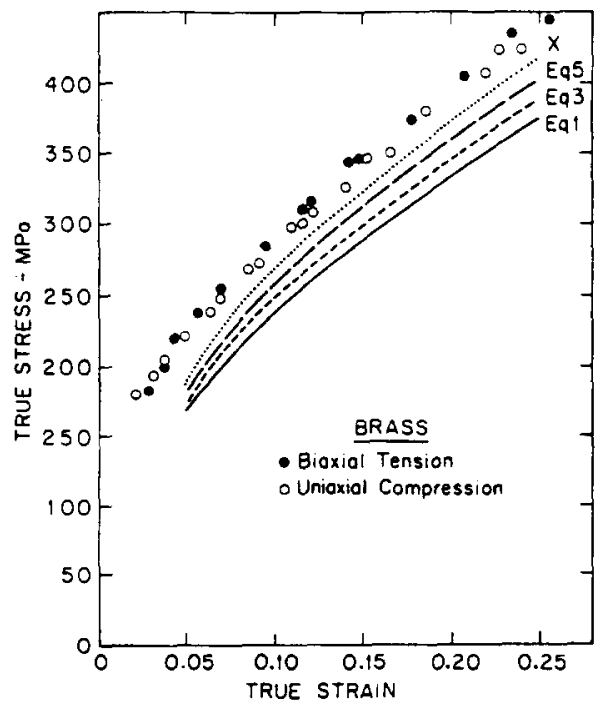

FIG. 7. Comparison of experimental biaxial tension and uniaxial compression points with predictions of various yield criteria from uniaxial tension, $X$, in the rolling direction. Predictions from equation (3) are based upon average tension results. 


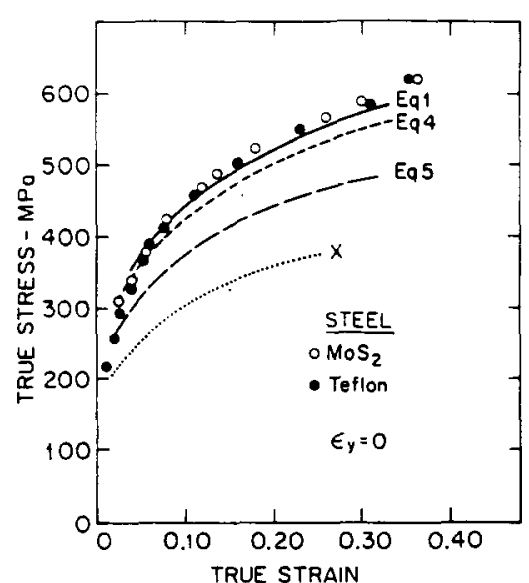

(a)

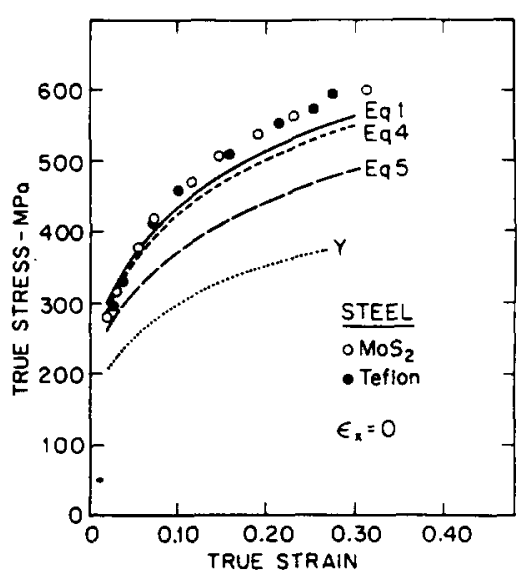

(b)

FIG. 8. Comparison of experimental plane-strain data with predictions of various yield criteria from uniaxial test, $X$, in the rolling direction (a) and $Y$, in the transverse direction (b). For equation (4), average tensile properties were used.

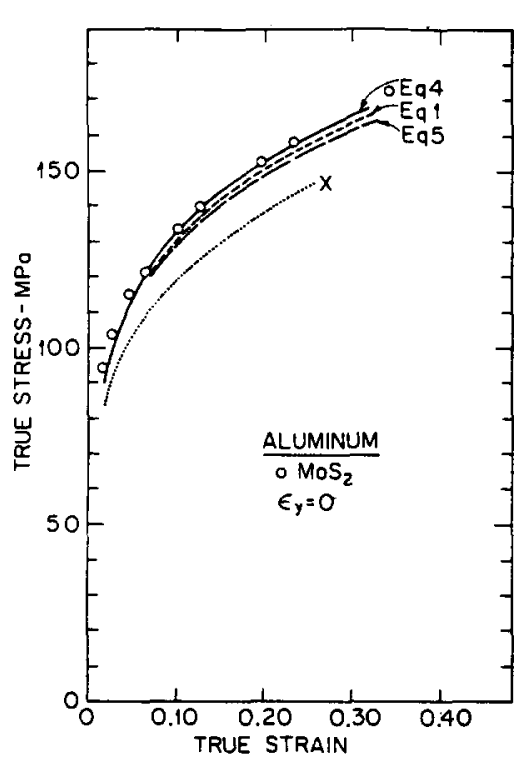

(a)

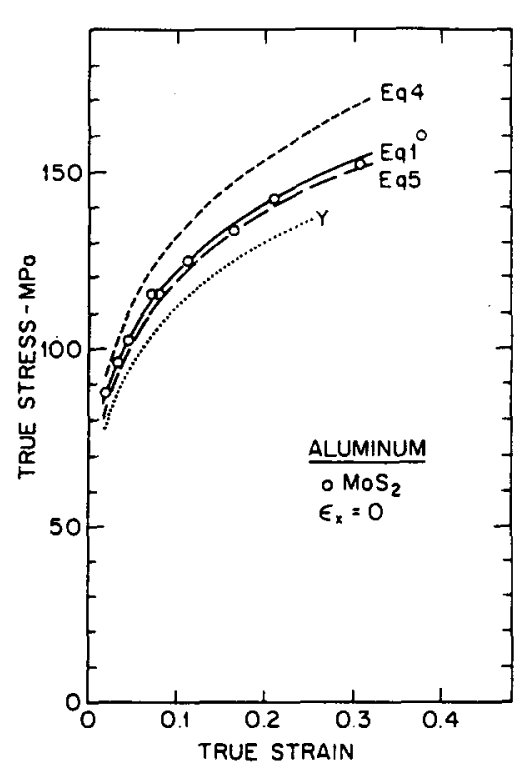

(b)

FIG. 9. Comparison of experimental plane-strain data with predictions of various yield criteria from uniaxial test, $X$, in the rolling direction (a) and $Y$, in the transverse direction (b). For equation (4), average tensile properties were used.

Table 4. Comparison of experimental and predicted ratios of flow stresses, $B / X$

\begin{tabular}{|l|c|c|c|c|}
\cline { 2 - 5 } \multicolumn{1}{c|}{} & \multicolumn{2}{c|}{ Experiment at $\varepsilon_{x}=0.1$} & \multicolumn{2}{c|}{ Theory } \\
\cline { 2 - 5 } & bulge test & $\begin{array}{l}\text { through-thickness } \\
\text { compression }\end{array}$ & $\begin{array}{c}\text { "old" Hill } \\
\text { Eq (1) }\end{array}$ & $\begin{array}{l}\text { Hosford } \\
\text { Eq (5) }\end{array}$ \\
\hline steel & 1.197 & 1.190 & 1.266 & 1.082 \\
aluminum & 0.969 & 0.938 & 0.851 & 0.961 \\
copper & 0.958 & 0.938 & 0.961 & 0.990 \\
brass & 1.055 & 1.036 & 0.925 & 0.981 \\
\hline
\end{tabular}




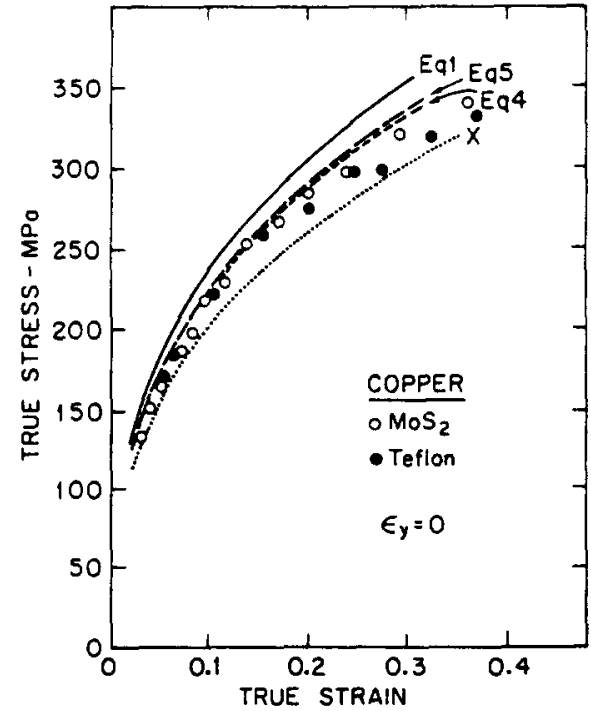

(a)

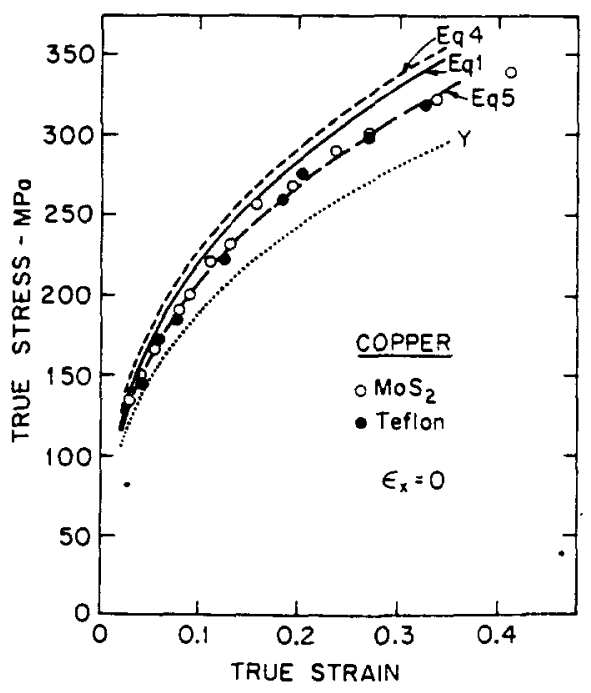

(b)

FIG. 10. Comparison of experimental plane-strain data with predictions of various yield criteria from uniaxial test, $X$, in the rolling direction (a) and $Y$, in the transverse direction (b).

For equation (4), average tensile properties were used.

\section{DISCUSSION OF RESULTS}

The excellent agreement between uniaxial compression and bulge tests in Figs. 4-7 indicates the bulge data are not low since friction in the compression test would, if anything, raise the compression curve above its true level (i.e. for frictionless conditions).

Friction and possible redundant strain in plane-strain compression should, if anything. cause the experimental curves to be too high. This should be kept in mind when comparing the experimental and theoretical curves.

It may be noted that values of the strain-hardening exponent, $n$, varied with the method of loading. This could be due to changes of texture during the tests or as an artifact of the testing procedure.

In comparing the overall results, no single criterion provided the best predictions for all combinations of materials and tests.

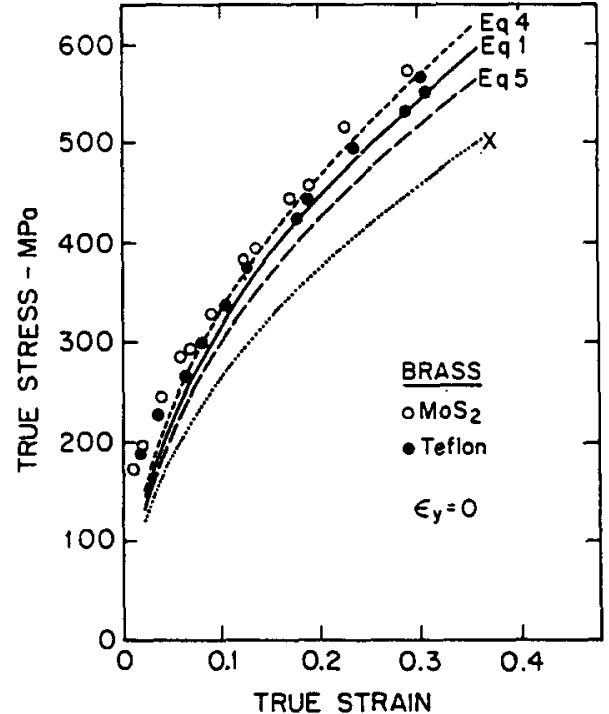

(a)

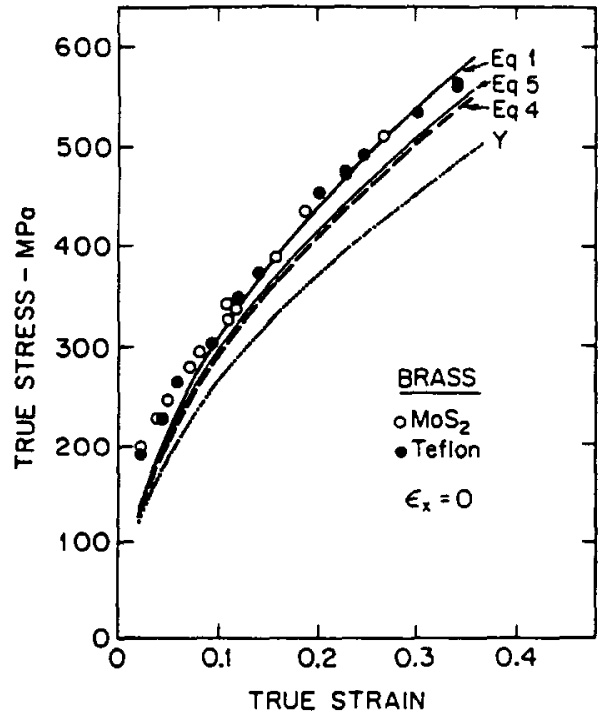

(b)

FIG. 11. Comparison of experimental plane-strain data with predictions of various yield criteria from uniaxial test, $X$, in the rolling direction (a) and $Y$, in the transverse direction (b). For equation (4), average tensile properties were used. 


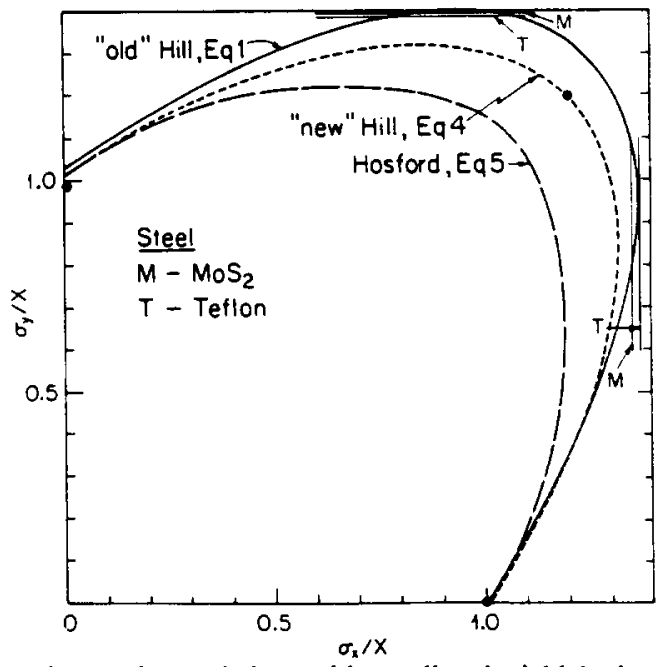

FIG. 12. Comparison of experimental data with predicted yield loci normalized to uniaxial tension, $X$, at a strain of 0.1 . Experimental data are indicated by solid points and by horizontal and vertical tangents obtained from plane-strain tests.

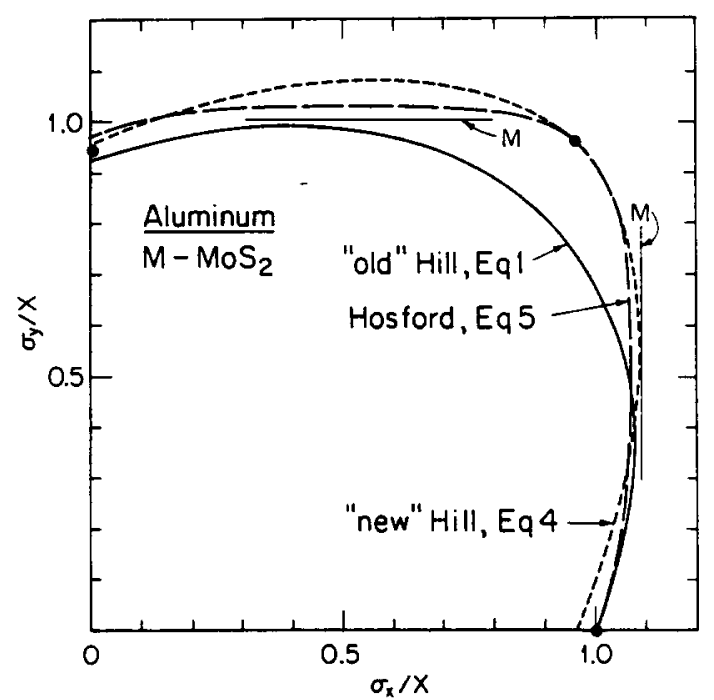

FIG. 13. Comparison of experimental data with predicted yield loci normalized to uniaxial tension, $X$, at a strain of 0.1 . Experimental data are indicated by solid points and by horizontal and vertical tangents obtained from plane-strain tests.

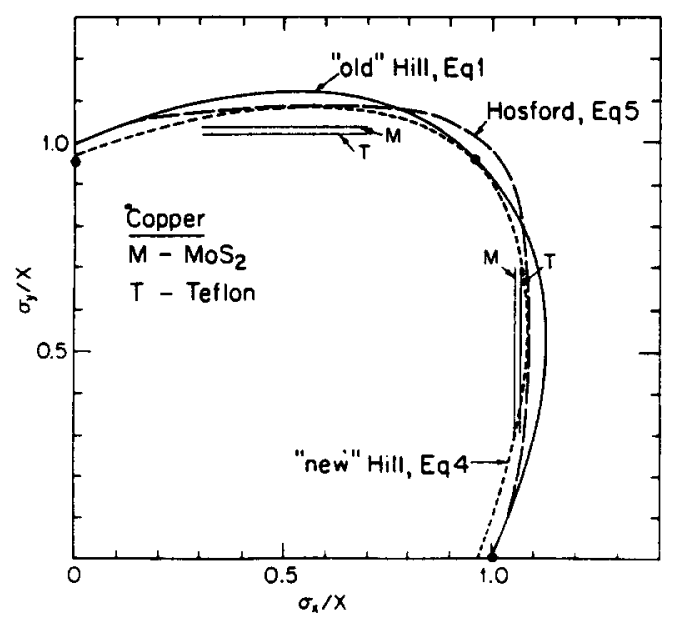

Fig. 14. Comparison of experimental data with predicted yield loci normalized to uniaxial tension, $X$, at a strain of 0.1 . Experimental data are indicated by solid points and by horizontal and vertical tangents obtained from plane-strain tests. 


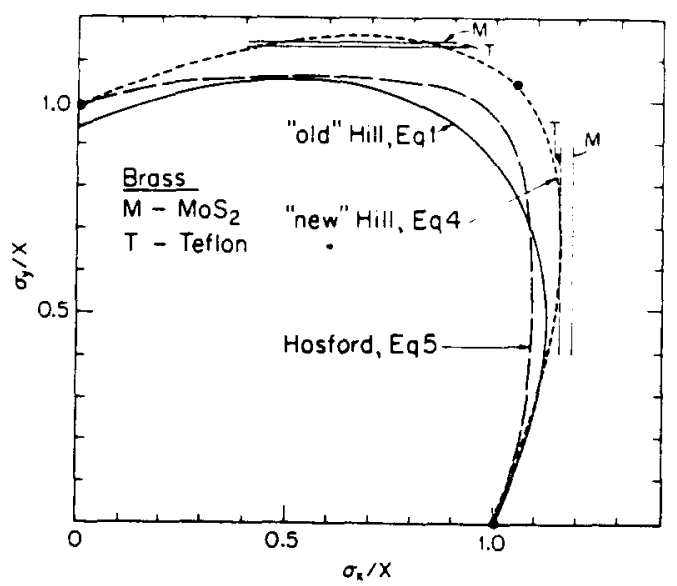

Fig. 15. Comparison of experimental data with predicted yield loci normalized to uniaxial tension, $X$, at a strain of 0.1 . Experimental data are indicated by solid points and by horizontal and vertical tangents obtained from plane-strain tests.

\section{DISCUSSION OF BULGE TESTING}

For the four materials, radii of curvature were measured as a function of pressure using both the optical technique already described and the more commonly used spherometer[15]. In all cases, the spherometer results indicated larger radii (which would lead to higher calculated stresses). Figs. 16(a,b) are typical.

As to strain measurements, values determined from the photographic grids were generally larger than those indicated by the extensometer [15]. A brief study was made to investigate why. By blueing the top of a copper specimen, indenting two gage marks and then bulging the specimen, the strain determined by the indicators (i.e. extensometer) was 0.325 . When the distance between the gage marks was measured accurately with a traveling microscope, a strain of 0.360 was computed. The conclusion is that the extensometer legs slipped relative to the specimen during bulging. If this is typical of these devices. the reported extensometer strains would be lower than their correct values. A combination of lower strains and higher stresses (due to larger radii mentioned above) would cause the calculated stress-strain curves to be higher than those determined from the optical techniques.

One last point concerns the biaxiality of both stress and strain during bulge testing. According to the flow rules associated with equations (1) and (5), balanced biaxial stress $\left(\sigma_{x}=\sigma_{y}\right)$ should not correspond to balanced biaxial strain $\left(\epsilon_{x}=\epsilon_{y}\right)$ if there is planar anisotropy. Fig. 17 shows the predicted variation of $\epsilon_{y} / \epsilon_{x}$ as

Table 5. Comparison of experimental and predicted ratios of flow stresses in plane strain to uniaxial tension

\begin{tabular}{|c|c|c|c|c|c|c|c|}
\hline & \multicolumn{4}{|c|}{ FSy $/ X$} & \multicolumn{3}{|c|}{ 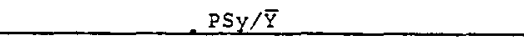 } \\
\hline Material & Lubricant & Experiment* & $\begin{array}{l}\text { Theory } \\
\text { "old" Hill } \\
\text { Eg (1) }\end{array}$ & $\begin{array}{l}\text { Hos ford } \\
\text { Eg (5) }\end{array}$ & Experiment" & $\begin{array}{l}\text { Theory } \\
\text { "new" Hili }\end{array}$ & $\begin{array}{l}\text { Exoonent, n, } \\
\therefore \approx \mathrm{Eq}(4)\end{array}$ \\
\hline Stee: & $\begin{array}{l}\text { Mos } \\
\text { TesIon }\end{array}$ & $\begin{array}{l}1.372 \\
1.350\end{array}$ & 2.363 & 1.190 & $\begin{array}{l}1.351 \\
1.334\end{array}$ & 1.305 & 2.002 \\
\hline Aluminum & $\operatorname{MOS}_{2}$ & 1.091 & 1.074 & 1.064 & 1.135 & 1.130 & $=.734$ \\
\hline Copper & $\begin{array}{l}\text { Hos } \\
\text { Teflon }\end{array}$ & $\begin{array}{l}1.051 \\
1.006\end{array}$ & 1.128 & 1.087 & $\begin{array}{l}1.090 \\
2.207\end{array}$ & 1.120 & $\therefore .743$ \\
\hline Drass & $\begin{array}{l}\text { Mos } \\
\text { Tafion }\end{array}$ & $\begin{array}{l}1.184 \\
1.154\end{array}$ & 1.123 & 1.086 & $\begin{array}{r}1.107 \\
1.167\end{array}$ & 1.167 & $\therefore .746$ \\
\hline
\end{tabular}

\begin{tabular}{|c|c|c|c|c|c|c|c|}
\hline \multicolumn{5}{|c|}{ PEXYY } & \multicolumn{3}{|c|}{$\mathrm{PS} x / \overline{\mathrm{Y}}$} \\
\hline & & & & & $\vdots$ & & \\
\hline & $\begin{array}{l}\because O S_{2} \\
\text { Tefion }\end{array}$ & $\begin{array}{l}1.407 \\
1.400\end{array}$ & 1.363 & 1.212 & $\begin{array}{l}1.376 \\
1.370\end{array}$ & 1.305 & $=.002$ \\
\hline Aluninum & $\operatorname{NoS}_{2}$ & 1.067 & 1.074 & 1.052 & 1.048 & 1.130 & $\therefore .734$ \\
\hline copser & $\begin{array}{l}\text { sos } \\
\text { refion }\end{array}$ & $\begin{array}{l}1.037 \\
1.063\end{array}$ & 1.129 & 1.079 & $\begin{array}{l}1.060 \\
1.049\end{array}$ & 1.120 & $\therefore .743$ \\
\hline Brass & $\begin{array}{l}\text { Nos } \\
\text { SefIor }\end{array}$ & $\begin{array}{l}1.150 \\
1.140\end{array}$ & 1.123 & d. .071 & $\begin{array}{r}1.154 \\
1.244 \\
\end{array}$ & 1.167 & $\therefore 740$ \\
\hline
\end{tabular}




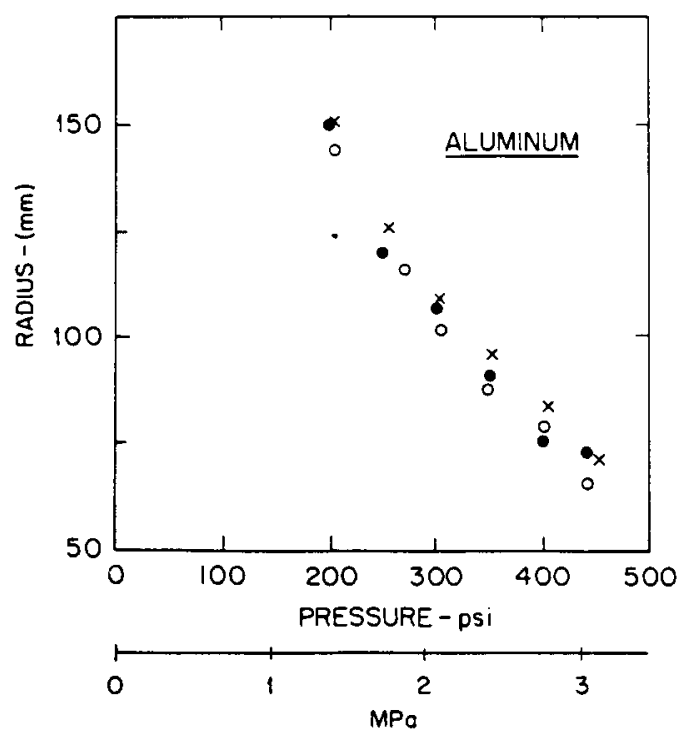

(a)

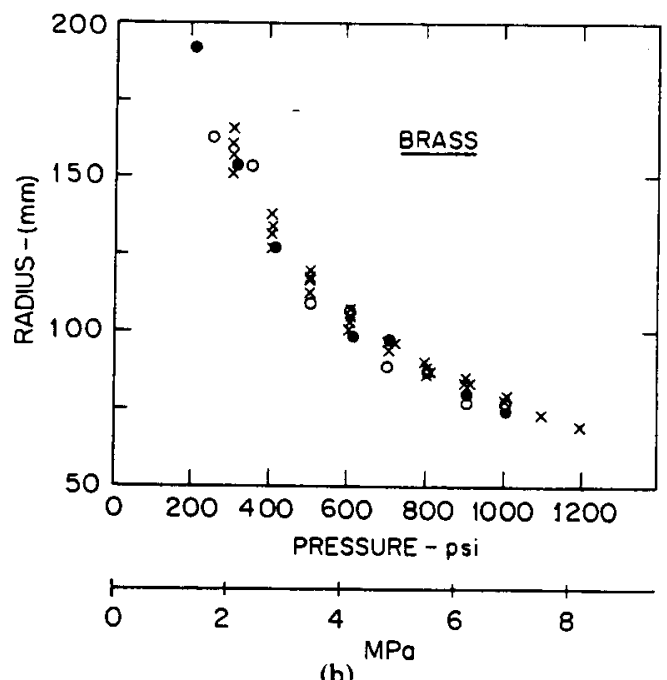

FIG. 16. Comparison of radii of curvature measured by the Duncan and Johnson spherometer and by the projected fringe technique for aluminum (a) and brass (b). Steel and copper showed similar trends. Spherometer results indicated by $x$, and optical fringe results by $O$ and for 0 and 90 degrees respectively.

a function of $\sigma_{y} / \sigma_{x}$ for two of the materials. However, in none of the bulge tests was there a statistically significant difference between the cadii of curvature in the $x$ and $y$ directions or the strains in those directions. The bulge test probably deviates slightly from both balanced biaxial stress and strain; an intermediate condition is more likely. If balanced biaxial stress prevailed, the deviation of strain from balanced biaxiality would be obvious from the data; it was not. On the other hand, if there were equal or nearly equal principal strains, the flow rules associated with equation (5) would predict a difference between principal stresses for aluminum of only $3.5 \%$. Equation (1) would predict a difference of $11 \%$. Both equations (1) and (5) predict a difference of $3.5 \%$ for the steel. Perhaps the differences of radii of curvature corresponding to a $3.5 \%$ difference in principal stresses are too small to observe.

If the two principal radii of curvature, $r_{x}$ and $r_{y}$ had been different, it is not clear how $\sigma_{x}$ and $\sigma_{y}$ could have been calculated directly from $r_{x}, r_{y}$, and the pressure. Studies with elliptical bulges [22, 23] have used measured strains with an assumed yield criterion and its associated flow rules to evaluate $\sigma_{x}$ and $\sigma_{y}$. Clearly this is questionable when the intent is to determine the appropriate yield criterion.

\section{CONCLUSIONS}

(1) No single yield criterion used in this study gives best agreement for all of the combinations of materials and tests investigated. 


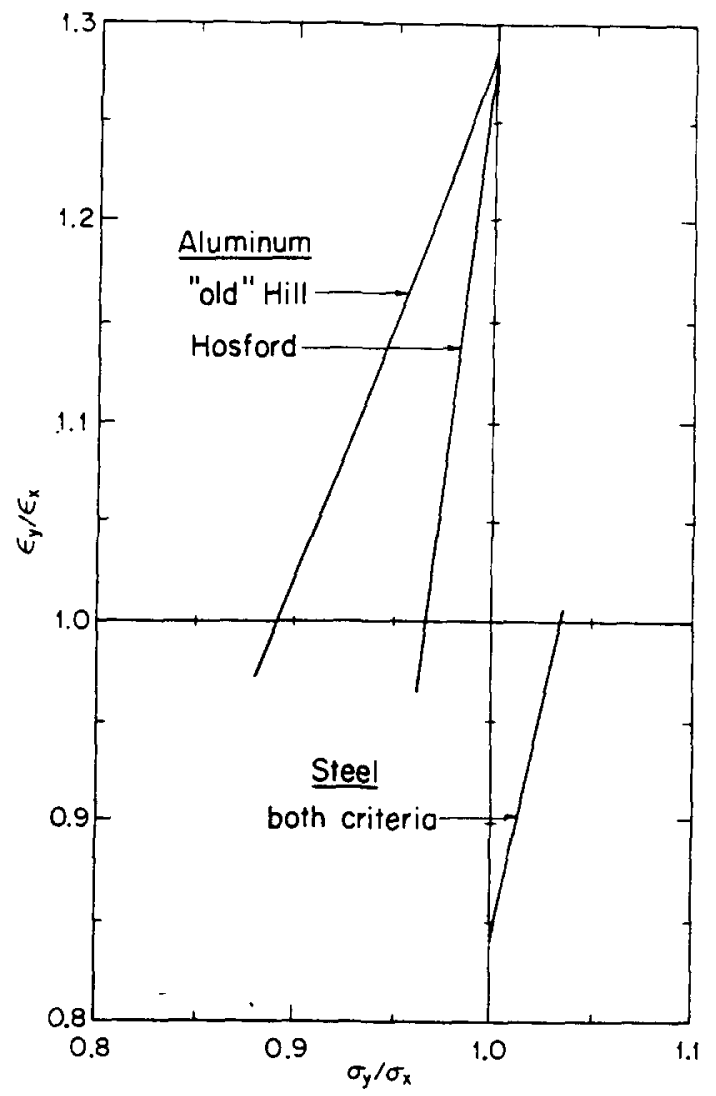

FIG. 17. Comparison of the strain ratios, $\epsilon_{v} / \epsilon_{x}$, as a function of the stress ratio, $\sigma_{v} / \sigma_{x}$, predicted from the flow rules corresponding to equations (1) and (5) using experimental strain ratios $R$ and $P$.

(2) The "new" Hill criterion, which requires additional test data for predictive purposes, generally does not provide a better fit to the plane-strain data than the "old" Hill criterion or the Hosford criterion.

(3) Biaxial stress-strain curves determined by bulge testing using a projected fringe technique agree closely with those obtained by through-thickness compression testing.

(4) The radii of curvature in bulging measured by a projected fringe technique were lower than those measured by the Duncan and Johnson spherometer at the same pressure.

(5) The "old" Hill criterion was better for predicting bulge test results for the steel and copper while the Hosford criterion was better for the aluminum and brass.

Acknowledgements-This work was conducted under NSF grant DMR-7923231. The authors wish to thank Carol Bobroff, Tor Holdoe and Carroll Hass for assistance in many of the experiments. We also thank C. M. Vest for his advice and help with the optical system.

\section{REFERENCES}

1. R. HiLl, Proc. Roy. Soc. London, SER. A, 193281 (1948).

2. R. HILL, Mathematical Theory of Plasticity. p. 317. Clarendon Press, Oxford (1950).

3. A. N. Bramley and P. B. Mellor, Int. J. Mech. Sci. 8, 101 (1966).

4. R. M. S. B. Horta, W. T. ROBERTS and D. V. WiLsON, Int. J. Mech. Sci. 12, 231 (1970).

5. R. PEARCE, Int. J. Mech. Sci. 10, 995 (1968).

6. A. J. Ranta-Eskola, Metals Techn. 7, 45 (1980).

7. A. J. RaNTA-ESKola, Int. J. Mech. Sci. 21, 457 (1979).

8. A. N. Bramely and P. B. Mellor, Int. J. Mech. Sci. 10, 211 (1968).

9. R. Hill, Math. Proc. Cambridge Phil. Soc. 85, 179 (1979).

10. A. Parmar and P. B. Mellor, Int. J. Mech. Sci. 20, 385 (1978).

11. R. H. WAGONER, Met. Trans. A, 11A, 165 (1980).

12. J. WoOdThorPe and R. PeARCE, Int. J. Mech. Sci. 12, 451 (1970).

13. W. F. Hosford, Seventh N. Amer. Metals. Res. Conf. Proc., p. 191 (1979). 
14. R. W. LogAn and W. F. Hosford, Int. J. Mech. Sci. 22. 419 (1980).

15. J. L. DuncaN and W. Johnson, Sheet Metal Ind. 42, 271 (1965).

16. T. D. Dudderar. F. B. KoCH and E. M. Doerries, Exp. Mech. 17, 133 (1977).

17. C. M. VEST. Private communication (1981).

18. C. M. VEST, Holographic Interferometry. Wiley, New York (1979).

19. W. Johnson and P. B. MELLOR, Engineering Plasticity. pp. 115, 204. Van Nostrand Reinhold, London (1973).

20. A. B. WatTs and H. Ford, Proc. Inst. Mech. Engrs. B1, 448 (1952).

21. J. M. Alexander, J. Mech. Phys. Solids 3, 233 (1955).

22. C. C. Chow, A. W. Dana and G. Sachs, Trans. AIME 185. 49 (1949).

23. J. L. Duncan and W. Johnson, Int. J. Mech. Sci. 10, 143 (1968). 